\title{
College-University Transfer Experiences of Students With Disabilities: A Survey Study
}

\author{
Charles Anyinam ${ }^{1}$, Celina Da Silva ${ }^{2}$, Sue Coffey ${ }^{3}$, Frank Smith ${ }^{4}$, Christine Arnold ${ }^{5}$, Bill Muirhead ${ }^{6}$, Ellen Vogel ${ }^{3}$ \\ \& Rick Vanderlee ${ }^{1}$ \\ ${ }^{1}$ School of Nursing, Nipissing University, North Bay, Canada \\ ${ }^{2}$ School of Nursing, York University, Toronto, Canada \\ ${ }^{3}$ Faculty of Health Science, Ontario Tech University, Oshawa, Canada \\ ${ }^{4}$ National Educational Association for Disabled Students, Ottawa, Canada \\ ${ }^{5}$ Faculty of Education, Memorial University of Newfoundland, St John's, Canada \\ ${ }^{6}$ Faculty of Education, Ontario Tech University, Oshawa, Canada \\ Correspondence: Charles Anyinam, School of Nursing, Nipissing University, North Bay, Ontario P1B 8L7, \\ Canada.
}

Received: June 11, 2020

Accepted: July 23, 2020

Online Published: July 31, 2020

doi:10.20849/ijsn.v5i3.755

URL: https://doi.org/10.20849/ijsn.v5i3.755

\begin{abstract}
The benefits of postsecondary education (PSE) are well documented and yet historic challenges have contributed to significant underrepresentation of students with disabilities. This paper presents the results of a survey study that explored students with disabilities' experiences of transfer between PSE institutions in Canada. Data was collected using a survey questionnaire developed by the research team. Rating questions were analyzed using descriptive data. Students also answered open-ended questions that were analyzed using a qualitative content analysis approach. Sixty-nine of the 248 survey responses received indicated involvement in transfer between PSE institutions, mostly college to university. Four out of 5 of the transfer students self-identified as having psychiatric and mental health disabilities (e.g., anxiety, depression). Perceptions and experiences among successful and non-successful transfer students were mixed. Fully one-third of transfer students indicated that they felt that college-university transfer may be a better route for PSE for students with disabilities than going straight to university. Barriers to college-university transfer, among others, included a lack of information about who can assist with the process $(62.5 \%)$ and inadequate information about disabilities and accommodation (56.3\%). The results of this snapshot of PSE students with disabilities' perceptions of college-university transfer may inform the design of evidence-based PSE transition interventions for this population. Additionally, given the under-representation of Indigenous and other racialized students in PSE, there is merit in further investigation focusing on their transfer experiences.
\end{abstract}

Keywords: postsecondary education, students with disabilities, Canada, transition, college-university transfer, survey research

\section{Introduction}

\subsection{Introduce the Problem}

Postsecondary education is one driver of competitiveness within the Canadian economy, yet access to equitable postsecondary education (PSE) is lacking for individuals with disabilities (Finnie, Childs, \& Wismer, 2011). In Canada, students with disabilities access and attain PSE credentials at lower rates than those without disabilities (McCloy \& DeClou, 2013). The 2012 Canadian Survey on Disability reported that $20 \%$ of individuals with disabilities do not hold a high school diploma compared to only $11 \%$ of individuals without disabilities (Arim, 2015). There is a large underrepresentation of students with disabilities in PSE nationally. For example, in Ontario, $84 \%$ of students without disabilities will enroll in some form of PSE by the age of 21 compared to only $68 \%$ of students with disabilities (McCloy \& DeClou, 2013).

This disparity is in part driven by lower university participation and degree attainment rates and offset by higher college participation and credential attainment rates (Finnie et al., 2011; McCloy \& DeClou, 2013). Data from 
the 1980 s to early 2010 s reveals that the gap between the two groups has remained relatively unchanged (Boothby, \& Drewes 2006; McCloy \& DeClou, 2013). Students with disabilities versus those who do not experience disability are reported to have higher rates of leaving their PSE programs prior to successful completion (Woods, Cook, \& McCloy, 2013). Sattler (2010) notes that underrepresented students often leave postsecondary programs due to health-related problems and time management issues, reporting that they felt a lack of support in both the academic and non-academic realms. Similarly, Tsagris and Muirhead (2012) reported longer timelines to graduate for PSE students with disabilities as they often leave and return to college and university multiple times due to the complexity of their disability and social needs.

Students with disabilities in Canada are also more likely to transition from college to university programs through mechanisms such as bridging opportunities where academic credit is awarded in the university program for coursework completed at the college level. Johnson, Zascavage, and Gerber (2008) note that while there is no reported difference in grade point average (GPA) between students with disabilities who enrolled directly into a university program and those who began in a two-year college program and transitioned to a four-year program, there is a higher rate of successful completion for those who transitioned from college to university.

\subsection{Importance of the Problem and Research Design}

Addressing the challenges and barriers experienced by students with disabilities in accessing and attaining PSE credentials requires a multi-faceted approach (National Educational Association of Disabled Students (NEADS), 2018b), beginning with an understanding of their experiences in PSE. Moreover, given that research indicates a disparity between college and university participation and graduation rates for students with disabilities versus those without, the transfer experience between college and university sectors must be viewed as a critical consideration in this context. To that end, we undertook an online survey study to explore the PSE transfer experiences and perceptions of students with disabilities.

\section{Method}

A partnership was formed between researchers at Ontario Tech University, Durham College, Memorial University of Newfoundland, Nipissing University, York University and NEADS to conduct research focusing on the transfer experience of students with disabilities in Canada. Fortuitously, NEADS was in the process of conducting research to examine the current landscape of accessibility services, accommodations, technical equipment and supports for students with disabilities at publicly funded postsecondary institutions across Canada. The focus on the experiences and perceptions of PSE students with disabilities involved in transfer was not specific to the NEADS Landscape Survey study, and therefore the Transfer Survey study was complementary to the NEADS study focus, while not overlapping it. The Transfer Survey study was approved and monitored by the Research Ethics Boards of the educational institutions research team members were affiliated with.

\subsection{Measurement Instrument}

Throughout the summer and fall of 2017, the research team collaborated with the NEADS Landscape Survey study team to create the Transfer Survey study questionnaire to collect data from PSE students with disabilities specifically about their perceptions and experiences of academic credit transfer between PSE institutions (i.e., college and university). The Transfer Survey study questionnaire was developed based on insights from the research literature and expertise of team members familiar with the subject matter. The questionnaire underwent an iterative design process involving team members meeting several times to discuss the drafts of the questions, pretesting the questions, and making changes prior to the start of the study. The categories of questions included in the Transfer Survey study questionnaire were: 1) demographic information about the PSE students (i.e., age, gender, disability type), 2) experiences and perceptions of transfer between PSE institutions, 3) barriers and facilitators to transfer, and 4) student recommendations for system improvements.

In nesting the Transfer Survey study within the NEADS study, we were able to gain insight into PSE students with disabilities' experiences and perceptions of transfer between PSE institutions, and compare various responses between students involved in transfer and those who were not. To undertake these comparisons a transfer question (Question \#12) was added to the NEADS study that enabled us to categorize students and create comparison groups. Question \#12 asked the following:

Please indicate if you have been involved in college-university transfer. This type of transfer refers to when students start out in a college program and switch over to a university program. For it to be considered a transfer, you must get academic credit for the courses you have already taken.

() I have transferred between a college and university program

( ) I was/am thinking about transferring or trying to transfer 


\section{( ) I applied to transfer but wasn't able to}

( ) I have not been involved in college-university transfer

\subsection{Sample and Sampling Procedures}

The sample sought for this study was individuals with disabilities who currently attend or recently graduated from a Canadian PSE institution. In Canada the way in which disability is perceived has steadily been changing with a shift away from the medical model of disability to a social model approach (Furrie, 2018). From the social model perspective disability is viewed as a phenomenon resulting from the interaction between persons with conditions/impairments, and attitudinal and social factors that negatively affect their ability to be independent and active participants in society. Thus, for the purposes of this study, disability is operationalized broadly to include a wide range and degree of mental, physical, and cognitive conditions and impairments that can: a) exist independently or in multiples, 2) be congenital, developmental or acquired through injury or aging, and c) be temporary, intermittent or permanent (Ontario Human Rights Commission (OHRC), n.d.).

The two-part survey questionnaire was distributed online to the participant pool beginning in late spring 2018 until late Fall 2018 through NEADS' organizational communication channels (i.e., website, membership list, national listserve, social media such as Facebook and Twitter). Subsequent to the initial distribution, 2 follow-up invitations were sent out through the membership list and national listserve.

\section{Results}

\subsection{Involvement in Transfer Between PSE Institutions}

A total of 248 survey responses to the two-part questionnaire were recorded (137 completed and 111 partially completed survey responses). While the questionnaire was launched nationally, consistent with NEADS membership, the responses were heavily weighted toward students attending PSE in Ontario; more than 4 out of 5 PSE students who completed the survey were from Ontario. Of the 248 survey responses, 190 participants answered question \#12, with more than one third $(n=69,36.3 \%)$ indicating they had been involved in transfer between PSE institutions (i.e., having transferred, thinking about transferring, applied to transfer but unsuccessful). Of these 69 students, the majority were enrolled as full-time students $(85.9 \%)$ and had successfully completed a transfer from a college to a university program $(n=46)$.

\subsection{Demographic Data}

\subsubsection{Age, Gender and Race/Ethnicity}

Age distributions between transfer and non-transfer students were very similar (see Table 1). The largest number of students within both groups reported a birth year between 1995-1999. However, on average, transfer students indicated age ranges that were slightly older than non-transfer students. The majority identified their gender as female, with slightly more females among the non-transfer group $(61.9 \%$ for transfer students vs. $69.3 \%$ for non-transfer students). The percentage of respondents who self-identify as male was almost equal for both groups. A small number of students (14.3\% for transfer students; $5.4 \%$ for non-transfer students) identified a gender other than male or female (i.e., trans male, trans female, non-binary, fluid, queer or other). Lastly, the majority indicated their race/ethnicity as Caucasian, with proportionately more transfer students than non-transfer students identifying in this manner (65\% vs. 54\%). Among both transfer and non-transfer participants, few self-identified as having Indigenous ancestry $(14.3 \%$ for transfer students; $4.2 \%$ for non-transfer students).

\subsubsection{Disability Type and Age of Onset of Disabilities}

For both transfer students and non-transfer students, psychiatric and mental health disabilities (including anxiety and depression) were the most highly reported (50\% for transfer students; $52.1 \%$ for non-transfer students). When psychiatric disabilities and mental health challenges were combined, approximately 4 out of 5 respondents in both the transfer and non-transfer category self-identified with these types of disabilities (see Table 1). Among both groups, approximately 1 in 4 respondents self-identified as having a disability associated with chronic illness (25\% for transfer students; $28.1 \%$ for non-transfer students) and attention deficit hyperactivity disorder (ADHD) (23.4\% for transfer students; $22.3 \%$ for non-transfer students).

Additionally, a similar distribution was seen between both groups in that close to 1 in 5 students self-identified as having a learning disability (18.8\% for transfer students; $19 \%$ for non-transfer students). Much higher representation of disability associated with acquired brain injury was seen among transfer students (10.9\%) compared to non-transfer students $(0.8 \%)$. Likewise, mobility/functional disability was more than twice as prevalent in the sub-group of transfer students ( $21.9 \%$ for transfer students; $9.1 \%$ for non-transfer students). 
Lastly, more than 1 in $5(20.3 \%)$ transfer students and 1 in 4 (27.3\%) of non-transfer students indicated that they were born with their disability. For transfer students, the second most frequent response was onset/acquisition between ages 6 to 12, while for non-transfer students, the second highest response category was between ages 13 to17. Amongst both the transfer and non-transfer students, a notable number indicated that their age at onset of their disability was ages 18 to 22. When asked if they were enrolled in PSE when they acquired their disability, the majority of both transfer and non-transfer students indicated they were (54.8\% for transfer students; $57.4 \%$ for non-transfer students).

\subsection{Experience and Perceptions of Transfer Process}

The data presented in this section represents a descriptive overview of student responses to questions on the Transfer Survey study questionnaire about their experience and perceptions of transfer between PSE institutions. That experience could include having successfully transferred, thinking about transferring, or having applied to transfer but been unsuccessful. Of the students who indicated they were involved in transfer $(n=69), 42$ elected to complete the Transfer Survey study questionnaire. Of these students two indicated they had tried to transfer and been unsuccessful, 7 were considering or in the process of transferring and 33 successfully transferred. Among students who successfully transferred, $45.2 \%$ transferred from college to university where the programs were not officially connected. Another $19.4 \%$ transferred where there was a formal articulation agreement. The remainder were either unsure if there was an agreement or preferred not to respond.

\subsubsection{Onset of Transfer Planning and Knowledge of Transfer}

Students were asked at what point they began thinking about college-university transfer. More than half of those who had successfully transferred indicated that they began thinking about transfer after starting college $(22.6 \%)$ or after doing well in college (32.3\%). Only $16 \%$ indicated that they began thinking of transfer in high school.

Transfer students were also asked how much they felt they knew about college-university transfer, with responses ranging from "nothing" to "everything they needed to know". For those who had an unsuccessful transfer or were in the process of transferring, more than half indicated they knew "nothing to very little", while an equal number indicated they knew "some things" or "everything they needed to know" about transferring. Students who successfully transferred responded to the same question. Interestingly, their responses reflected more confidence in their knowledge of transfer. Almost $84 \%$ of students who successfully transferred indicated that they knew "some things", "lots of things", and/or "everything they needed to know".

\subsubsection{Transfer Credits Received}

In the Transfer study, we asked students who successfully transferred to approximate how much of their university program they received credit for by the number of semesters of their program. Almost one quarter $(22.6 \%)$ indicated they received credit for 4 semesters or more, with $19.4 \%$ receiving credit for 3 semesters, $12.9 \%$ for 2 semesters, and $19.4 \%$ for 1 semester.

Table 1. Student demographics

\begin{tabular}{lll}
\hline Variable & Transfer: n (\%) & Non-Transfer n (\%) \\
\hline Gender & & \\
\hline Female & $26(61.9)$ & $52(69.3)$ \\
\hline Male & $10(23.8)$ & $19(25.3)$ \\
\hline Other* & $6(14.3)$ & $4(3.9)$ \\
\hline Age (Year of Birth) & & \\
\hline $1990-1999$ & $19(48.7)$ & $44(61.1)$ \\
\hline $1980-1989$ & $14(35.9)$ & $20(27.8)$ \\
\hline $1970-1979$ & $2(5.1)$ & $4(5.6)$ \\
\hline $1969-$ later & $4(10.2)$ & $4(5.7)$ \\
\hline Indigenous Ancestry & $6(14.3)$ & $3(4.2 \%)$ \\
\hline Race/Ethnicity & & $40(54.1)$ \\
\hline Caucasian & $26(65)$ & \\
\hline
\end{tabular}




\begin{tabular}{|c|c|c|}
\hline Black & $5(12.5)$ & $7(9.5)$ \\
\hline East Asian & $3(7.5)$ & $10(13.5)$ \\
\hline Latin American & $1(2.5)$ & $1(1.4)$ \\
\hline South Asian & $2(5)$ & $5(6.8)$ \\
\hline Southeast Asian & $2(5)$ & $2(2.7)$ \\
\hline West Asian & $2(5)$ & $3(4.1)$ \\
\hline Mixed origin & $3(7.5)$ & $8(10.8)$ \\
\hline \multicolumn{3}{|l|}{ Marital Status/Children } \\
\hline Not married & $31(73.8)$ & $60(82.2)$ \\
\hline Married & $5(11.9)$ & $8(11)$ \\
\hline Widowed & $1(2.4)$ & 0 \\
\hline Separated/Divorced & $2(4.8)$ & $1(1.4)$ \\
\hline Children & $7(16.7)$ & $8(11.1)$ \\
\hline \multicolumn{3}{|l|}{ Type of Disability $^{+}$} \\
\hline Psychiatric/Mental health & $32(50)$ & $63(52.1)$ \\
\hline Mental health Challenge & $21(32.8)$ & $30(24.8)$ \\
\hline Learning Disability & $12(18.8)$ & $23(19)$ \\
\hline Attention Deficit/ Hyperactive Disorder & $15(23.4)$ & $27(22.3)$ \\
\hline Autism Spectrum & $4(6.3)$ & $9(7.4)$ \\
\hline Acquired Brain Injury & $7(10.9)$ & $1(0.8)$ \\
\hline Chronic Illness & $16(25)$ & $34(28.1)$ \\
\hline Mobility/Functional Disability & $14(21.9)$ & $11(9.1)$ \\
\hline Blind/ Partly sighted & $6(9.4)$ & $9(7.4)$ \\
\hline Other & $7(10.9)$ & $4(3.3)$ \\
\hline \multicolumn{3}{|l|}{ Enrollment Status } \\
\hline Full-time & $55(85.9)$ & $100(82.6)$ \\
\hline Part-time & $9(14.1)$ & $21(17.4)$ \\
\hline
\end{tabular}

*Includes participants indicated their gender as trans male, trans female, non-binary, fluid, queer, or other

+ Participants were asked to select all that apply; most common disabilities are listed

\subsubsection{Use of Resources and Services}

Students were asked several questions related to the resources and services they utilized while attending PSE, most notably, those designated for students with disabilities. When asked if they attended orientation at their institution, the majority of both transfer and non-transfer students responded that they attended orientation. Yet between the two groups there was an observable gap, with far fewer transfer students attending orientation activities (58.1\% vs. $71.8 \%)$.

Participants were also asked to identify if they were registered with the accessibility services (formerly referred to as disability services) at their college or university. The vast majority of both transfer and non-transfer students $(92.7 \%$ and $92 \%$, respectively) indicated that they were registered at their institution. Similarly, among both transfer and non-transfer students, approximately $90 \%$ indicated they used the accommodations afforded to students within their institutions.

\subsection{Benefit and Challenges Associated With College-University Transfer}

Students involved in transfer were asked to comment on the degree to which they held a positive or negative perception of college-university transfer and what benefits they perceived. Among unsuccessful transfers, 
one-third held a somewhat positive perception, while the remainder held no view, preferred not to answer, or had neither a positive nor negative perception. For successful transfers, $43.8 \%$ held either a somewhat or very positive view of college-university transfer, while $21.9 \%$ held somewhat negative or very negative perceptions.

Fully one-third of students indicated that they felt that college-university transfer may be a better route for PSE for students with disabilities than going straight to university. Additionally, approximately 3 in 10 respondents indicated that: 1) there was lots of information specific to disabilities and accommodation $(28.1 \%), 2)$ good support for transfer students with disabilities at university after switching over (31.3\%), and; 3) universities were receptive to students with disabilities $(31.3 \%)$. Almost $28 \%$ indicated that systems and processes related to disabilities and accommodations were manageable, and colleges were receptive to students with disabilities. At the same time, $25 \%$ indicated that colleges provided good support for transfer students with disabilities prior to transferring to university.

Students were also asked to share their perceptions of barriers to college-university transfer. Amongst successful transfers at least half indicated that: 1) there was a lack of information about who can help with the process $(62.5 \%), 2)$ there was not enough information specific to disabilities and accommodation $(56.3 \%)$, and 3$)$ there was not enough support for transfer of students with disabilities at universities after switching over (46.9\%). Successful transfer students with disabilities also indicated they experienced a range of general challenges when transferring. Overwhelmingly, they indicated: 1) difficulty finding or confirming requirements for transfer credit $(60 \%)$, inconsistent or inadequate information about the transfer process $(53.3 \%)$, lack of guidance on application procedures (50\%), complicated and time-consuming application processes $(43.3 \%)$, lengthy timelines for decisions (43.3\%), and fewer transfer credits than expected (40\%).

\subsubsection{Benefits and Challenges Associated With Disability in the Transfer Process}

Students who successfully transferred from college to university were asked to comment on challenges they experienced, and the benefits in the transfer process specifically related to disability (e.g., accessibility services). About half indicated they did not experience any disability-related challenges nor perceived any benefits related to their disability. However, almost one-quarter of successful transfers indicated that they did experience disability-related challenges, while $24 \%$ indicated that they had experienced benefits associated with their disability. Lastly, $23 \%$ elected not to say whether they experienced challenges or benefits related to their disability.

Perceived challenges were associated with accessibility services, accommodation, and new processes. Some successful transfers highlighted associated benefits with the same disability-related services and processes involved in college-university transfer. Self-identified benefits included receiving support (including disability supports and counselling), accommodations, priority for residence, a more open community of students with disabilities, and receiving a diagnosis.

\subsubsection{Successful Transfer Student Perceptions of Advising Services}

Students who had successfully completed a college-university transfer were asked to comment on their experience with advising services at their college and university in terms of their helpfulness in general and their helpfulness in advising related to disability and accommodation. Responses indicated that, the majority of students found advising services at both their college and university to be somewhat helpful in general and in relation to disability-specific foci. Of note, almost one quarter of respondents indicated that they were not aware of advising services at their college or did not use advising services for either general issues $(23.3 \%)$ or disability related foci $(30 \%)$. These numbers are smaller for their university advising services, but still $13.8 \%$ indicated that they either were not aware of advising services or did not use advising services in general or for disability-related foci.

\subsubsection{Satisfaction With Transition Experience}

Finally, students who had successfully completed a transfer from college to university were asked to indicate how satisfied they were with their transition experience to university. Approximately one-third were satisfied or very satisfied (34.5\%), 41.4\% were neutral, and $13.7 \%$ were either dissatisfied or very dissatisfied, with $10.3 \%$ preferring not to say. While one might hope that more than one third of transfer students with disabilities would indicate some degree of satisfaction with their transition experience, the relatively low rate of dissatisfaction may be considered reassuring.

\subsection{Student Recommendations for System Improvements}

We also asked students an open-ended question on the Transfer Survey study questionnaire inquiring about their recommendations to improve their transfer experience from college to university. The majority identified the 
following recommendations: 1) clear information about timelines for transfer decisions, 2) consistent communication about the status of transfer credit(s), and; 3) better policies and procedures about the transfer process. A few students indicated that they would have liked to meet other students with a disability who had transferred and learn about their experience. Also, students suggested that there should be more collaboration between advising services at colleges and universities to provide students with the transfer information that they require in a more streamlined way.

\section{Discussion}

\subsection{Participant Characteristics}

The population of PSE students with disabilities is diverse, multi-faceted, and not easily profiled in the Canadian context (NEADS, 2018a). This notwithstanding, the students in our Transfer Survey study demonstrated characteristics similar to those identified in the broader population of PSE students with disabilities. For instance, it is not surprising that a large majority of the students in our study reported transferring from college to university. Within the literature ( Finnie, Childs, \& Wismer, 2011; McCloy \& DeClou, 2013; NEADS 2018a; Robson, Anisef, Brown, \& Parekh, 2014), it is well established that there is lower university participation and degree attainment rates among Canadians with disabilities that is offset by higher college participation and credential attainment rates (Finnie et al., 2011; McCloy \& DeClou, 2013). Almost twice as many PSE students with disabilities in Canada attend non-university public or private institutions (NEADS 2018b). Carter, Coyle, and Donald (2012) note that in general, college to university transfer is increasing for reasons that include the perception of college as a stepping stone to university, financial considerations (colleges, particularly those that are public, tend to offer cheaper tuition fees), locality, entrance GPA requirements, and opportunities for part-time study.

Finne et al.'s (2011) research indicates that there are both direct and indirect effects of having a disability on PSE attendance including high school variables i.e., grades, social support, and parental behaviour. Specific to college and university transfer there is not much information about why students with disabilities chose college over university and their reasons for subsequently transferring to university. Findings from Milsom and Sackett's (2018) study of the college-university transfer experience indicate that rejection from degree-granting institutions and the need to ease into PSE attendance were among reasons participants chose to attend college first. While it is clear that credit transfer between college and university has become a commonplace pathway in the PSE landscape in Canada (Ontario Colleges Application Service (OCAS), 2020), further research examining students with disabilities' reasons for choosing to transfer between college and university is needed to inform robust interventions that will appropriately direct students with disabilities into this pathway but also avoid unnecessary use of transfer as a means of attaining university credentials. Findings from such investigations could also inform recruitment and retentions efforts at both levels of PSE.

In this study, we found that compared to those who had not transferred, college-university transfer students were slightly older, less likely to be female and more likely to identify as Caucasian. These finding are consistent with the characteristics of PSE students with disabilities in Canada. Analysis of the 2012 Canadian Survey on Disability by NEADS (2018b) reported that compared to their non-university counterparts, university students with disabilities are younger and more likely to be female. Concerning students with disabilities in PSE from diverse backgrounds (e.g., students identifying as Indigenous) national data reveal that these students are more likely to attend college than university (NEADS, 2018b; Robson et al., 2014). Very few of the students in this study identified as Indigenous persons; however, there was three times larger representation of Indigenous students with disabilities among the transfer group compared to the non-transfer group (transfer students 14.3\%; non transfer students 4.2\%; general population 4.9\%)(Statistics Canada, 2020). While Indigenous Canadians over the age of 15 are far more represented at the college level than the university level (Ottmann, 2013; Robson et al., 2014) the PSE participation and credential attainment rates between Indigenous persons and the total population do not compare (Ottmann, 2013). The relatively high representation of Indigenous students with disabilities among the transfers group highlight transfer as a possible viable means through which university level credentials can be accessed by students with disabilities with complex intersectional identities. Indeed, our findings impress that given what is known about under-representation of Indigenous and racialized persons in general in PSE in Canada and potentially the intersection of self-identification as both disabled and belonging to a racialized group, furthering research from an intersectional perspective is important.

Over the last 30 years, the number of students with disabilities attending PSE has increased. This has largely been driven by significant increases in the number of students with non-visible disabilities ((NEADS, 2018b). Of these, learning disabilities followed by mental health and chronic-illness related disabilities are the most 
common type reported by students. In contrast, the number of students with physical or sensory disabilities has remained relatively constant. These trends are mostly reflected in the type of disabilities reported by both non-transfer and transfer students; although, consistent with national population data for individuals aged 15-24 years (largely capturing the majority of post-secondary students), psychiatric and mental health disabilities and not learning disabilities were the most commonly reported. Among study respondents, 4 out of 5 self-identified with a psychiatric or mental health disability (e.g., anxiety, depression, schizophrenia), and only 1 in 5 self-identified as having a learning disability.

\subsection{Experiences and Perceptions of College-University Transfer}

Although there is sizable body of literature focusing on students with disabilities' educational transfers, much of this corpus is non-Canadian-centric and addresses the transition from high school to PSE or PSE to the labour force. There is a dearth of information about PSE students with disabilities' beliefs, perceptions and experiences related to academic credit transfer between PSE institutions. Our study is novel in the Canadian context; students' responses to the Transfer Survey study questionnaire about their perceptions and experiences of college-university transfer provided a number of insights that contribute to what is known and understood about PSE students with disabilities.

\subsubsection{Planning and Academic Advising}

In our study, findings related to the point at which students began planning college-university transfer and knowledge about the transfer process were interesting and somewhat unexpected, warranting further investigation. Among students who successfully transferred only $16 \%$ indicated they began thinking of transfer in high school. This is an interesting finding in that students who have not begun a process of anticipatory planning toward transfer may find they are not in a program with an articulation agreement that maximizes credit transfer or that there is not a pathway for transfer. The data suggests that this may have been the case for students. The majority of successful transfer students with disabilities transferred in circumstances where there was not an official relationship between programs or institutional articulation agreement.

Further examination of the point at which students with disabilities begin to think of college-university transfer will be helpful in determining when decision points occur and the context for decision-making. Recent research suggests that the extent to which PSE students prepare for transfer may have a significant impact on their post-transfer experience and their likelihood of success. Berger and Malaney (2003) have suggested that students who are best informed and have taken steps to actively prepare for transfer are most likely to achieve academic success and be more satisfied in the university environment. Similarly, Fisk (2018) found that in the transition from high school to college, students who had high quality transition plans had positive outcomes such as a higher GPA. Thus, it stands to reason that ensuring that high school teachers, high school guidance counsellors, and members of the community are aware of the many opportunities associated with college-university transfer and the processes involved may be an important factor in promoting not only greater awareness, but also greater anticipatory planning in relation to college-university transfer amongst students with disabilities.

\subsubsection{Academic Advising}

Academic advising has been identified as a cornerstone of student success in PSE (Chan et al., 2019; Lee \& Schneider, 2016; Smith \& Allen, 2019). In their study of PSE transfer students, Lee and Schneider (2016) found that academic advising is most positively associated with the persistence of these students. Given the potentially positive impact that academic advising can have on the success of transfer students with disabilities, the finding in our study that some transfer students were not aware of or did not use academic advising related to transfer or disability-related foci is concerning and warrants further inquiry. Gaining a better understanding of why some students with disabilities are not aware of or chose not to use the service may go a long way towards addressing the low rate of university credential attainment among Canadians with disabilities.

\subsubsection{Perceptions and Experiences of Transfer}

In terms of experiences related to transfer, the picture that emerges is one that is mixed- where some students who have successfully transferred reported positive perceptions and experiences (e.g., receiving good support for transfer prior to and after transfer) and see this route as potentially more optimal than direct entry to university. On the other hand, a sizable number of students with disabilities who have successfully transferred held more negative perceptions and identified multiple challenges associated with this PSE experience, including challenges with systems, processes, supports, and information. Although further data collection is needed, it would appear from this response pattern that the experience of college-university transfer for students who are successful in transferring is not always a positive one. Research focusing on the overall population of students 
who transfer from college to university lends some validity to this conjecture. For example, through phenomenological research, Milsom and Sackett (2019) concluded that college-university transfer students with disabilities experiences paralleled those of students without disabilities and also identified positive and negative experiences specifically related to their disabilities. Additionally, Gilliland (2018) found that college-university transfer students experienced negative and positive experiences related to transfer, both of which were a source of motivation.

When asked what transfer students found beneficial about college-university transfer, a fair number were inclined to view college-university transfer as a better route for those with disabilities. This is an important finding in that it may potentially have value for students with disabilities and their families seeking to make decisions about PSE participation. For PSE students with disabilities it may be that attending college first provides an opportunity to "try out" PSE, building transferable skills, capacity and confidence to pursue and persist at the university level. Recent research supports this premise; Hurrell, Shawcross, and Keeling's (2019) investigation of transfer experiences found that for students transferring from vocational education to university, vocational education equipped them with transferable skills relevant to university study. Similarly, but in the direction of university to college transfer, Lui (2016) found that transfer improved college completion for students struggling at the university level. Gleaning better insight into how and why college-university transfer is a better route for some students with disabilities will aid PSE service providers, high school counsellors, family and students in seeking and providing information to support decisions-making around access to PSE that is the best fit for each student.

Similar to the finding of recent research conducted by Milsom and Sackett (2018), some students in our study had positive experiences and perceptions about the transfer process such as; receiving support and accommodations. Unfortunately, others reported barriers and challenges to transfer consistent with those cited in the literature by students in general, including 1) overly complicated transfer system and policies; 2) lack of, inconsistent, or insufficient information regarding the transfer process; and 3) lack of guidance and communication through the process. In addition to these transfer barriers and challenges, PSE students with disabilities' experiences of transferring are made more arduous by having to unnecessarily deal with barriers and challenges related to their disability. Similar to our findings, Milsom and Sackett (2018) found that transfer students with disabilities perceived a lack of support and experienced challenges related to disability services and accommodations. Tsagris and Muirhead's (2012) study examining transfer experiences between a college and university found that when attempting to transfer PSE students with disabilities experienced difficulty with transferring their disability documentation related to accommodation and were often required to complete additional or repeat assessments. Taken together, these findings bolster the case that creating more streamlined, transparent systems in which information is readily available and accessible, processes are as straightforward as possible, and timelines are reasonable and adhered to may be essential in promoting successful college-university transfer for students with disabilities.

\section{Recommendations}

Addressing the challenges and barriers experienced by students with disabilities in accessing, persisting, and attaining PSE credentials requires a multi-faceted approach, beginning with an understanding of who they are and their experiences in PSE. Given that well-established data reveals a disparity between college and university participation and graduation rates for students with disabilities versus those without, the transfer experience between college and university sectors must be viewed as a critical consideration in this context. The results of this study encourage consideration of the following recommendations to support students with disabilities in PSE:

1. Examining in greater detail the prevalence, experience, and difficulties associated with mental health challenges and psychiatric disabilities among transfer students with disabilities is an essential next step.

2. Understanding what factors influence college-university transfer choices and college-university transfer opportunities among various sub-groups of students with disabilities, including those associated with ethnicity, are important considerations. In particular, given the under-representation of Indigenous persons in general in PSE, exploring in greater detail the higher representation of persons self-identifying as Indigenous within the transfer student group (compared to the non-transfer student group) would be important.

3. Ensuring that high school teachers, high school guidance counsellors, and members of the community are aware of the many opportunities associated with college-university transfer and the processes involved to promote greater anticipatory planning in relation to college-university transfer amongst students with 
disabilities.

4. It is important that all PSE institutions invest in robust, multifaceted orientation programs particularly for those with disabilities given the complexity that transfer students with disabilities describe around entering a new system.

5. Streamlining the transfer and recognition of prior disability assessments is essential so that these assessments, and the resulting accommodations, can follow students from high school to PSE and through whatever pathways they may take within the PSE system.

6. Streamlining mechanisms to make the process of transfer more transparent and ensuring there are service providers knowledgeable about and sensitive to the unique needs and experiences of students with disabilities may help to offset the barriers currently experienced by transfer students with disabilities.

7. Ensuring all transfer students, including those with disabilities, are aware of the range of services available through advising services and how to access these services is essential. While data would suggest many transfer students may not attend orientation in which this type of information is typically reviewed, alternate mechanisms for creating awareness about advising services among students with disabilities and transfer students is essential.

\section{Limitations}

Our study provides new insights while confirming previous findings of studies about PSE students with disabilities' perceptions and experiences with transfer between college and university; however, our findings must be interpreted with some caution. First, the sample size is relatively small. It is difficult to determine if it is representative of the population of interest in that this group has not been previously studied to any great extent in the Canadian context. Second, the sample mostly reflects students attending PSE in the province of Ontario. While Ontario's population accounts for more than one third of the Canadian population, students from the province are overrepresented in the study. Third, given that the majority of the students transferred from college to university, these results may not reflect the perspectives and experiences of students with disabilities who transferred from university to college.

\section{Conclusion}

Increasing participation of students with disabilities in PSE is vital to achieving the full contribution of people with disabilities in society. Addressing this challenge is not only of key importance to future economic competitiveness, it lies at the very heart of beliefs embedded within Canadian culture, society, and the PSE system itself about equity and justice (Finnie, Mueller, Sweetman, \& Usher, 2010). Understanding individuals with disabilities' experiences within PSE is an important starting point, yet there is little that is known about the educational experiences and pathways taken by this group of students. The study presented in this paper was conducted to redress this paucity. The findings are significant in broadening our understanding of the ways in which students with disabilities navigate the postsecondary education landscape in Canada. This study has shined a light on college to university transfer as a viable means for students with disabilities to successfully attain post-secondary credentials. This notwithstanding, there are a number of barriers and challenges, such as lack of information or coordinated services between and within institutions, that make this pathway a hurdle for students already faced with challenges in accessing and persisting in PSE. Looking forward, it will be important to consider the numerous recommendations emerging from this study and in particular, further examine Indigenous learner's transfer needs and the available resources to address them. In addition, the development of evidence-informed transfer support programs and the implementation of transfer assessments to facilitate successful PSE outcomes for students with disabilities is warranted.

\section{Acknowledgements}

This study was supported through a grant from the Ontario Council on Articulation and Transfer (ONCAT). The authors would like to acknowledge the invaluable help they received from the National Educational Association of Disabled Students (NEADS) and their affiliated partners throughout the data collection process.

\section{References}

Arim, R. (2015). Canadian Survey on Disability, 2012. A profile of persons with disabilities among Canadians aged 15 years or older, 2012. Ottawa: Statistics Canada. Retrieved from https://www150.statcan.gc.ca/n1/pub/89-654-x/89-654-x2015001-eng.pdf

Berger, J. B., \& Malaney, G. D. (2003). Assessing the transition of transfer students from community colleges to a university. NASPA Journal, 40(4), 1-23. https://doi.org/10.2202/1949-6605.1277 
Boothby, D., \& Drewes, T. (2006). Returns to university, college and trades education. Canadian Public Policy, 32(1), 1-21. https://doi.org/10.2307/3552240

Carter, I., Coyle, J., \& Leslie, D. (2011). Easing the transfer of students from college to university programs: How can learning outcomes help?. Canadian Journal of Higher Education, 41(2), 10-27.

Chan, Z. C., Yan, C. H., Jason, C. H. C., Nga, C. S., Yan, N. K., Yiu, W. K., \& Kan, Y. P. (2019). Academic advising in undergraduate education: A systematic review. Nurse Education Today, 75, 58-74. https://doi.org/10.1016/j.nedt.2019.01.009

Finnie, R., Childs, S., \& Wismer, A. (2011). Under-represented groups in postsecondary education in Ontario: Evidence from the Youth in Transition Survey. Toronto: Higher Education Quality Council of Ontario. Retrieved from http://www.heqco.ca/SiteCollectionDocuments/UnderRepdGroupsENG.pdf

Finnie, R., Mueller, R. E., Sweetman, A., \& Usher, A. (2010). New perspectives on access to postsecondary education. Ottawa: Statistics Canada. Retrieved from http://www.statcan.gc.ca/pub/81-004-x/2010001/article/11152-eng.htm\#a

Fisk, A. K. (2018). An examination of transition planning practices in high school and college outcomes for students with disabilities. Doctoral dissertation, Alfred University Research \& Archives. Retrieved from https://aura.alfred.edu/bitstream/handle/10829/13563/Fisk_Amy_2018.pdf? sequence=5\&isAllowed=y

Furrie, A. (2018). Canadian survey on disability reports. The evolution of disability data in Canada: Keeping in step with a more inclusive Canada. Ottawa: Statistics Canada. Retrieved from https://www150.statcan.gc.ca/n1/pub/89-654-x/89-654-x2018003-eng.htm

Gilliland, M. L. (2018). The experience of community college transfer students in the process of attaining a Bachelor's degree at a regional public university. Doctoral dissertation, University of Alabama Libraries. Retrieved from https://ir.ua.edu/bitstream/handle/123456789/5180/file_1.pdf? sequence=1\&isAllowed=y

Hurrell, E. R., Shawcross, E., \& Keeling, E. (2019). How does a vocational qualification (BTEC) prepare students for a degree in biosciences at a research-intensive university?. New Directions in the Teaching of Physical Sciences, 14(1). https://doi.org/10.29311/ndtps.v0i14.3315

Johnson, G., Zascavage, V., \& Gerber, S. (2008). Junior college experience and students with learning disabilities: Implications for success at four-year universities. College Student Journal, 42(4), 1162-1168.

Lee, H., \& Schneider, T. (2018). Does posttransfer involvement matter for persistence of community college transfer students?. Community College Journal of Research and Practice, 42(2), 77-94. https://doi.org/10.1080/10668926.2016.1251351

Liu, V. Y. T. (2016). Do students benefit from going backward? The academic and labor market consequences of four-to two-year college transfer. New York: Centre for Analysis of Postsecondary Education and Employment. Retrieved from https://ccrc.tc.columbia.edu/media/k2/attachments/capsee-do-students-benefit-from-going-backward.pdf

McCloy, U., \& DeClou, L. (2013). Disability in Ontario: Postsecondary education participation rates, student experience and labour market outcomes. Toronto: Higher Education Quality Council of Ontario. Retrieved from http://www.heqco.ca/SiteCollectionDocuments/At\%20Issue\%20-\%20Disability\%20in\%20ON_ENG.pdf

Milsom, A., \& Sackett, C. (2018). Experiences of students with disabilities transitioning from 2-year to 4-year institutions. Community College Journal of Research and Practice, 42(1), 20-31. https://doi.org/10.1080/10668926.2016.1251352

National Educational Association of Disabled Students (NEADS). (2018a). Landscape of accessibility and accommodation in post-secondary education for students with disabilities. Ottawa: Author. Retrieved from https://www.neads.ca/en/about/media/AccessibilityandAccommodation\%202018-5landscapereport.pdf

National Educational Association of Disabled Students (NEADS). (2018b). Post-secondary students with Disabilities: their experience past and present: An analysis of the Statistics Canada 2012 Canadian Survey on Disability. Ottawa: Author. Retrieved from https://www.neads.ca/en/about/media/Final\%20reportCSD2012AdeleFurrie2-3.pdf

Ontario Colleges Application Service (OCAS). (2020). Credit transfer between colleges and universities in Ontario. Toronto: Author. Retrieved from https://www.ontariocolleges.ca/en/apply/transfer-credits

Ontario Human Rights Commission. (n.d.). The opportunity to succeed: Achieving barrier-free education for students with disabilities. Consultation report (pp. 45-65). Toronto: Author. Retrieved from 
http://www.ohrc.on.ca/en/book/export/html/2470

Ottmann, J. (2013). Indigenizing the academy: Confronting 'contentious ground'. Special 40th Anniversary Issue. The Morning Watch: Educational and Social Analysis, 42(1). Retrieved from http:/www.mun.ca/educ/faculty/mwatch/vol40/winter2013/indigenizingAcademy.pdf

Robson, K. L., Anisef, P., Brown, R. S., \& Parekh, G. (2014). The intersectionality of postsecondary pathways: The case of high school students with special education needs. Canadian Review of Sociology/Revue canadienne de sociologie, 51(3), 193-215. https://doi.org/10.1111/cars.12044.

Sattler, P. (2010). From postsecondary application to the labour market: The pathways of under-represented groups. Toronto: Higher Education Quality Council of Ontario. Retrieved from http://www.heqco.ca/sitecollectiondocuments/pse_eng.pdf

Smith, C. L., \& Allen, J. M. (2018). Predictors of advising learning. Journal of Student Affairs Research and Practice, 55(3), 270-284. https://doi.org/10.1080/19496591.2018.1474754

Statistics Canada. (2012). Canadian Survey on Disability. Ottawa: Author. Retrieved from https://www.statcan.gc.ca/eng/survey/household/3251

Tsagris, D., \& Muirhead, B. (2012). Evaluating postsecondary supports for Ontario students with learning disabilities. Toronto: Higher Education Quality Council of Ontario. Retrieved from http://www.heqco.ca/SiteCollectionDocuments/EvaluatingPSESupportsForStudentsWithLearningDisabilities.pdf

Woods, K. L., Cook, M., DeClou, L., \& McCloy, U. (2013). Succeeding with disabilities: Graduates with disabilities and the factors affecting time-to-completion. Toronto: Higher Education Quality Council of Ontario. Retrieved

from http://www.heqco.ca/SiteCollectionDocuments/Succeeding_with_disabilities_ENG.pdf

\section{Copyrights}

Copyright for this article is retained by the author(s), with first publication rights granted to the journal.

This is an open-access article distributed under the terms and conditions of the Creative Commons Attribution license (http://creativecommons.org/licenses/by/4.0/). 